\title{
Learning obstacle on the material circumference and area of triangle in Limpung junior high school number 2
}

\author{
Muhammad Prayito \\ Sekolah Pascasarjana, Universitas Pendidikan Indonesia \\ Jl. Setiabudi no. 229 Bandung \\ email: mprayito@gmail.com
}

\begin{abstract}
The purpose of this research was to analyze the characteristics of learning obstacle contained in the concept of circumference and area of a triangle in SMP N 2 Limpung. Data about learning obstacle Obtained through analysis of the results of the students' answers to the test and learning processes within the material circumference and area of triangles. This study is a qualitative study using of didactical design research method. The research result in learning identified material of circumference and area of a triangle were didactical, ontogenic and epistemological obstacle. As for learning obstacle found are: (1) distinguishing concept image material high line, bisecting line, line weight and line axis; (2) determine the high line on the triangular side of the base is not horizontal; (3) Determine the triangle area an obtuse triangle; and (4) visualization of the students regarding the ability to determine the type of triangle and the position of the perpendicular line or field.
\end{abstract}

\section{Introduction}

Batang has 62 Junior High School consisting of 15 private schools and 47 public schools. The school on Ranked by the UN in year 2013 Limpung Junior High School No. 2 with the number of 203 students was ranked 30 out of 62 School. The percentage of mastery of the material about the National Exam subjects of mathematics which contains materials of numbers, algebra, geometry, statistics and odds show that geometry has the lowest percentage. In the aspect of students' abilities of the elements and properties of geometry has a percentage of $35.96 \%$, while on the elements and properties of Flat has a percentage of $42.63 \%$. The condition put geometry into the most difficult material in the Mathematics National Exam.

Table 1. Percentage of mastery of the material of math at Junior High School 2 Limpung

\begin{tabular}{lll}
\hline No & Ability & $\begin{array}{l}\text { Percentage of } \\
\text { mastery }\end{array}$ \\
\hline 1 & Elements and geometrical properties (three dimension) & 35,96 \\
2 & The concept of probability theory & 38,67 \\
3 & Elements and properties Flat (dimension two) & 42,63 \\
4 & Operation numbers, social arithmetic, row / series & 42,94
\end{tabular}



tendency

(Source BSNP. 2014)

Geometry competence in competency standards amounted to two of the all competencies of totaling of 6 competencies. In the elaboration of indicators, there are 11 indicators of geometry achievement of 25 indicators, which means the percentage of indicators geometry on SKL is $44 \%$. Indicators are specified in SKL is largely as a problem-solving. Solving problems that exist in the indicator indicates a problem that by solved are the lated to everyday life, so therefore student needs to observe the actual object. Percentage of the number of items of geometry material on National Exam is $45 \%$. Each question has own characteristics. Problem solving not only resolve the issue in the context of mathematical or daily life in order to make the students become familiar to face similar problems, applying a mathematical procedure in the context of the new problem(Suryadi, 2012). Based on the analysis about the National Exam in 2013, 2014 and 2015, I get the data as follow:

Table 2. Number of questions on the geometry of the National Exam

\begin{tabular}{llll}
\hline No & Periode & geometry & Item number \\
\hline 1 & 2013 & 18 & $17,18,19,20,21,22,23,24,25$, \\
& & & $26,27,28,29,30,31,32,33,34$ \\
2 & \multirow{2}{*}{2014} & 16 & $12,21,22,23,24,25,26,27,28$, \\
& & \multirow{2}{*}{17} & $29,30,31,32,33,34,35$ \\
3 & 2015 & & $2,21,22,23,24,25,26,27,28,29$, \\
& & & $30,31,32,33,34,35,36$ \\
\hline
\end{tabular}

Based on the results of preliminary observations in Limpung Juonior High School No.2, learning activities have been centered on the learner. The learning activities in the study group who had planned of the teachers have been going well, although it is still limited to working on the activity sheets in groups. The questions are given in the student worksheet(LKPD) only to the problems in accordance with the material that has provide at the beginning LKPD example problems. This means that learners tend to follow the examples of questions.

According to Soedjadi (1991), Guttierez (1992) and Tall, D. (2004) the difficulties often are experienced by learners in learning geometry. for example, learners have difficult to determine a right angle to identify and understand space. This condition is found at all levels of education, both primary and secondary education. Furthermore Tall mention geometry can be realized conceptually like geometry Euclide while for non-Euclide can be imagine as visible its space of surface that is not flat. According to Bishop (1989), especially the visualization of geometry problems usually experienced individually by learners. It is often experienced by learners because each individual has a different variety of visual imaginary in mathematics learning activities. Also according to Mason (2009) to learn geometry formally learners requires thinking at a relatively high level. Learners must have the experience to think more deeply at lower levels before learning formal geometry concepts. 
Learning geometry can be improved by applying Van Hiele's learning level. Van Hiele level learning can bring learners to master the five-level thinking Van Hiele (Schwartz, J.E: 2010, Mason, M: 2009 and Pegg: 1985). Nasser (1992) use the learning level of the Van Hiele in his research to improve the learning outcomes of students of middle school in Brazil. Saad and Davis (1997) in his research found that spatial ability and language skills will greatly assist in the achievement of learning with learning theory Van Hiele on the geometry of space. Sutama, Suharta, and Suweken (2014) has developed a learning tool geometry SMA by Van Hiele theory based Wingeon. Research Sutama, Suharta, and Suweken show validity, practicability and effectiveness in the activities of learners and good learning outcomes.

Usiskin (1982), Burger (1986) and $\mathrm{Wu}$ (2006) are found different results on his research. They found that learners are not able to perform at the level of formal deduction. This means that learners can not be at the level 4, namely rigor. Wu research results found that the higher grade scores Van Hiele higher level. Based on the questions triangular and quadrilateral, nothing students from grades 1 to 4 are in level 3 and no grade 1 and 2 are on the second level.

\section{Van Hiele Theory}

According to Pierre Van Hiele and Dina van Hiele-Geldof in learning geometry students thinking development occurs through five (5) levels:

1) Level 0 (Visualization). The student reasons about basic geometric concepts, such as simple shapes, primarily by means of visual considerations of the concept as the whole without explicit regard to the properties of its components.

2) Level 1 (Analysis). The reasons students about geometric concepts by means of an informal analysis of the component parts and attributs. Necessary properties of the concept are established.

3) Level 2 (Abstraction). The student logically orders the properties of the concepts, definitions abstract forms, and can extinguishing between the necessity and sufficiency of a set of properties in Determining a concept.

4) Level 3 (Deduction). The student Formally reasons within the context of a mathematical system, complete with undefined terms, axioms, an underlying logical system, definition, and theorems.

5) Level 4 (Rigor). The student can compare different systems based on axioms and can study various geometries in the absence of concrete models.

According to Van Hiele every learner in learning the geometry through the levels above the same order. However, the time when learners can enter a different level. It is possible that at a certain part geometry, a learner has reached a rather high level, while on the other he is still at the lower level. the progress level of development of learners do not think a lot depends on the maturity, but much influenced by the learning process. Thus the good organization of the method, time, materials, and lesson plans that are used to a certain level can improve thinking ability of students in the learning materials. Van Hiele filed five phases of the learning sequence are:

1) Phase I: Information 
The students were introduced to the range of material. Teachers discuss the material to clarify the matter so that students understand the material coverage.

2) Phase II: Guided Orientation

In this phase, students are introduced to the objects of its properties will be abstracted by learners in learning. The purpose of this phase so that learners are actively engaged in exploring these objects. Teachers and guiding learners to explore the right, through the tasks carefully structured.

3) Phase 3: Eksplisitasi

In this phase, the intuitive knowledge that has been held back elaborated learners become more explicit. In this phase, learners are clearly aware of the conceptualization of the material he was studying geometry, and describe it in their own language. Teacher introduced mathematical terms that are relevant.

4) Phase 4: Orientation Free

In this phase, students solve problems whose solution requires the synthesis, utilization concepts and relations that have been elaborated upon. The teacher's role is to select material and geometry problems right, introduces terms that are relevant as required.

5) Phase 5: Integration

In this phase, the students make a summary of everything that has been learned (concepts, relationships) and integrate their knowledge into a coherent network that can be easily described and implemented. Language and conceptualization of mathematics used to describe this network. Finally, summarized idea and integrated into the formal mathematical structure. At the end of the fifth phase of this new level of thinking that has been achieved for the material in question.

\section{Methods}

This study was conducted by researchers to design instructional design learning analysis according obstacle experienced by learners in studying the geometry of class VII. The method used for this study is a qualitative research. Qualitative methods are used to obtain in-depth data, a data implies. The study design used by researchers in this study is didactical Design Research (DDR). The focus of this research was to determine the increase in mathematical problem-solving ability, visualization capabilities and independence of learners with the application of the Van Hiele theory on learning geometry.

Pursuant to Didi Suryadi (2010) study design didactic basically consists of three stages: (1) analysis of the situation didactic before learning that his form in the form of design didactic Hypotheses include ADP, (2) analysis metapedadidaktik, and (3) analysis retrosfektif namely the analysis linking the results of analysis of the situation didactic hypothesis with the results of the analysis metapedadidaktik. Of the three stages will be obtained Empirical Design didactic that it was likely to continue to be refined through three phases of the DDR. The population used in this study were students of class VII Junior High School N 2 Limpung, while the sample is class VIIB. 


\section{Results and Discussion}

Learning obstacle found in this study was found from their lessons in class. Learning Obstacle identified in circumference and area of triangle material includes didactical, ontogenic and epistemological obstacle. Learning begins with remembering previous material that is the next triangle in the material today entered the area and perimeter of triangles. Students are asked to open the textbook on page 246, then start learning by asking the formula area of a triangle is $\frac{1}{2} \times a \times t$. She explained about the broad concept setiga. Teachers use a rectangular piece of paper to explain to students how to find the area of rectangle first, and then the teacher explained to students on a diagonal line. after the students already understand the diagonal line, the teacher continued to cut diagonal lines to create two triangles. Next look for the conclusion of a rectangle that is $2 \mathrm{x}$ area of the triangle then found the area of a triangle is $1 / 2 \mathrm{x}$ area of the rectangle. After explaining all the concepts and all the students already know, the students were told to take down first. before entering into the core material the teacher should ask what the sense of the triangle that students are knowing better clearer about the triangle. students have difficulty when asked to show the high line when teachers triangle shown no side horizontal.

Overall, the concentration of students in considering the material. students who occupy the front row tend to pay more attention, and the majority are women. student sitting in the back row of the majority of men, tend to be less. but there is one student sitting in row number 2 which looks sleepy tried to pay attention. Almost all of the students responded well during the learning process, but there are only a few students who stand out. Student difficulties seen when teachers provide comprehensive material obtuse triangle, when students are asked to find a high line in an obtuse triangle. Teacher gives less motivation to students, some students did not dare to ask questions or express opinions. teachers do not feed that positive feedback, when there are students who can solve exercises. From the placement of student seating not too ideal, because the students are split between male and female so that less free in their social interactions, and there is one student who has a small sitting posture behind so as to assess and note she found it difficult. Many students are distracted and wrong focus when the cameraman runs. Classroom atmosphere conducive, as evidenced when students focus with each note.

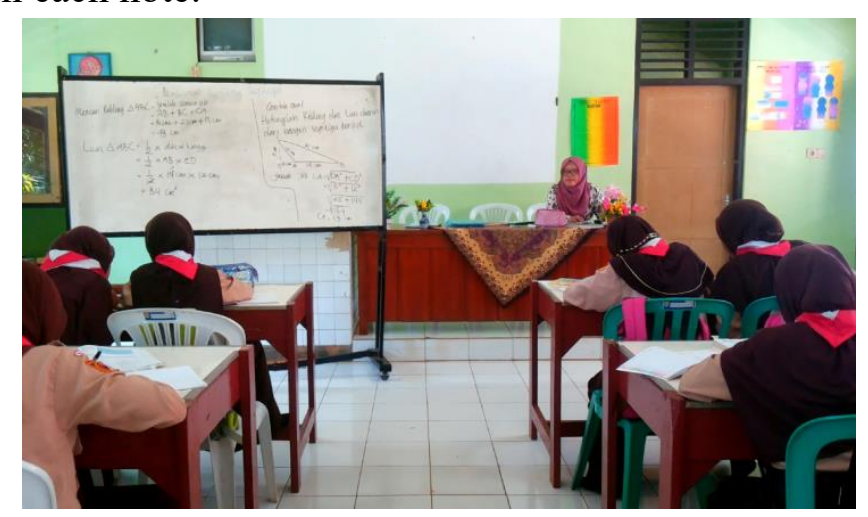

Figure 1. Learning process to determine the triangle area of an obtuse triangle 
In the minutes to 34-36 students have time to record and teachers could sit down. I found one male student sitting on the right rear looks less enthusiasm for writing the material identified by the teacher, but the teacher less attention. There is also a male student sitting to the left rear chatting with friends and looking into the camera it is also less noticed by the teacher. My analysis of the notes above are: Master-class managing well with a loud voice, the order of writing on the chalkboard systematically arranged and clearly. At the time of writing the material identified students by the teacher, the teacher does not see activity student sitting behind or do not get around to checking the entire class. Teachers completed examples of questions that have been given to students, so that students are not given the opportunity to work at the front, while the students already know and understand the material. Teachers did not master the material around the triangle, the side tilt is unknown, thus making the students' difficulties in completing the sample questions. Teachers can anticipate well and quickly, so as not to complicate learners. Students can find some problems with the way the feedback from teachers.

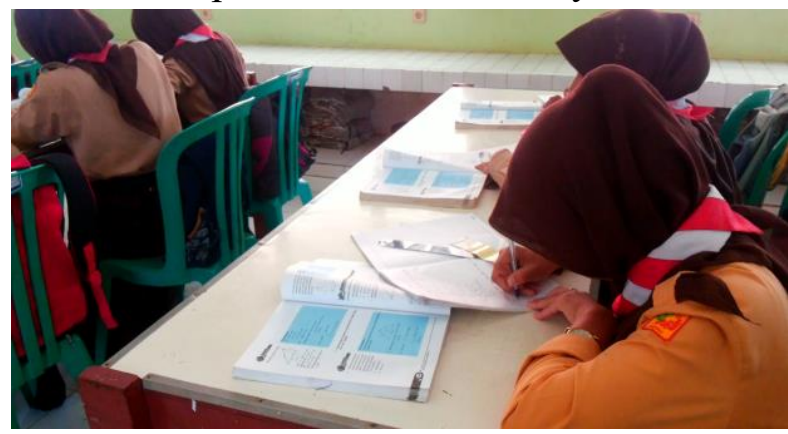

Figure 2. Student activity in discussion

In the learning process a teacher to control the students, when students complete exercises, the teacher gives the student aid that difficulty in doing. Teachers stimulate students' activity. When doing similar exercises, at number 2 multiple students using different ways in order to write the formula, there is a detail, there is only directly insert formulas and numbers. When the study ended teacher also gave attention to the students to give a conclusion together and remind students to learn at home. differentiating concept image material high line, the dividing line, line weight and line axis. It is proved that the visualization capabilities of students is still low, with regard to the ability to determine the type of triangle. Students learning result for answer question number 4 are 8 student can correct answer and 24 student has wrong answer. Question number 5 only 6 student can correct answer. This result agree with Soedjadi(1991), Usiskin(1982) and $\mathrm{Wu}(2006)$ that student have difficulty in visualization. It means student in SMP N 2 Limpung grade 7 still in level 0 van hiele. 


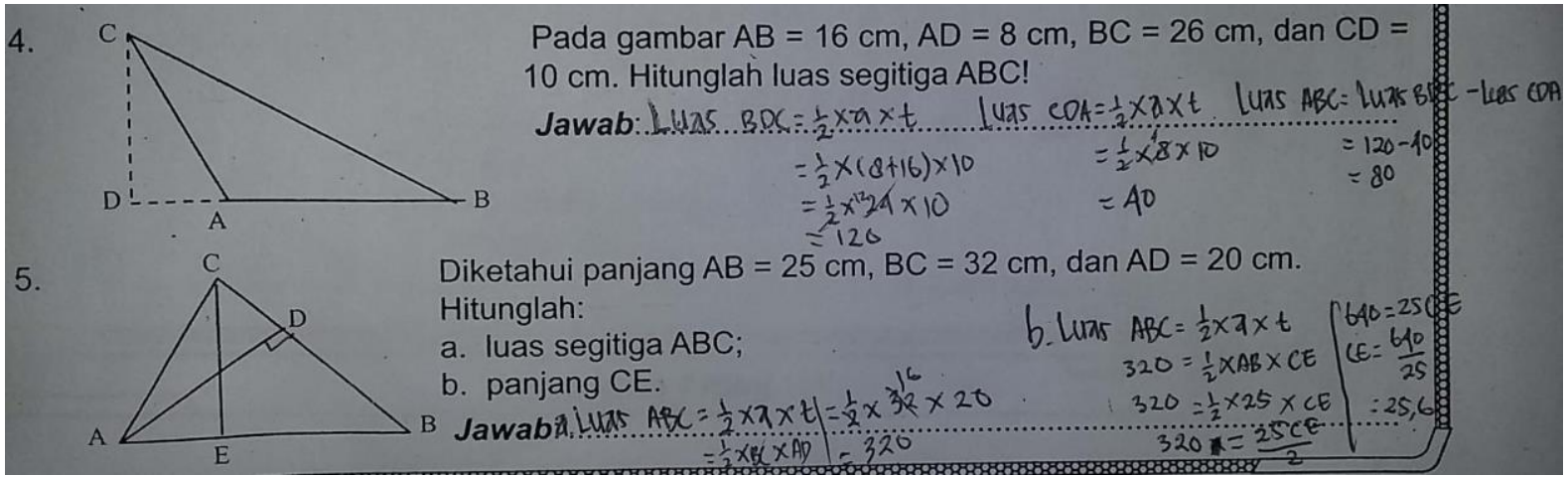

Figure 3. answer the student

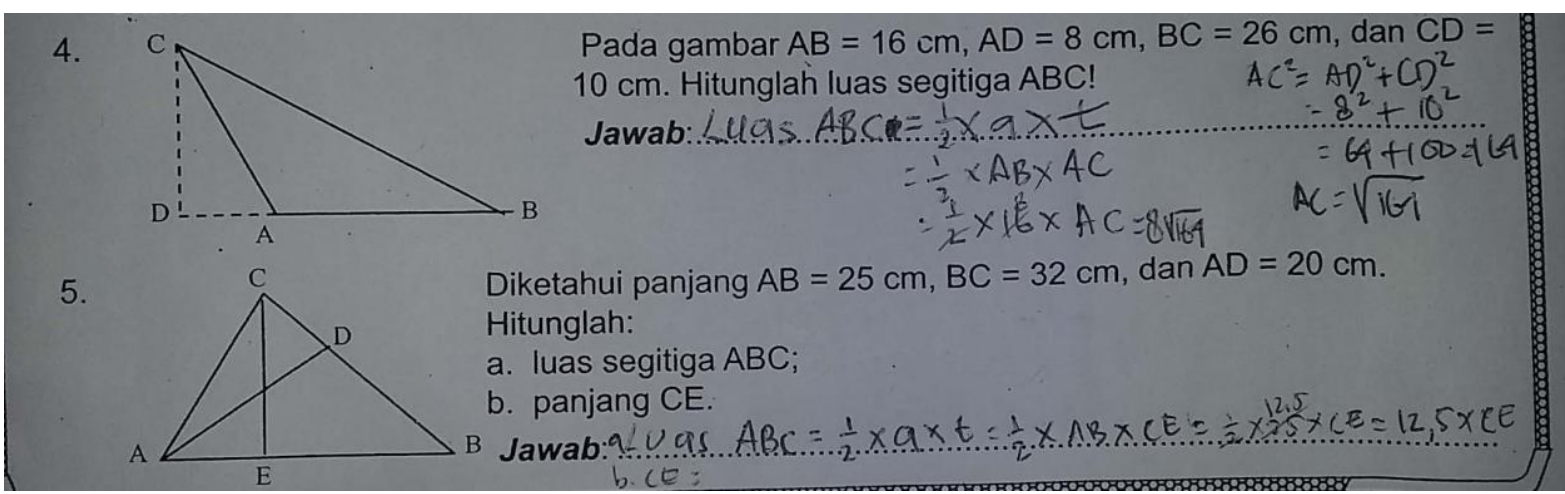

Figure 4. other answer the student

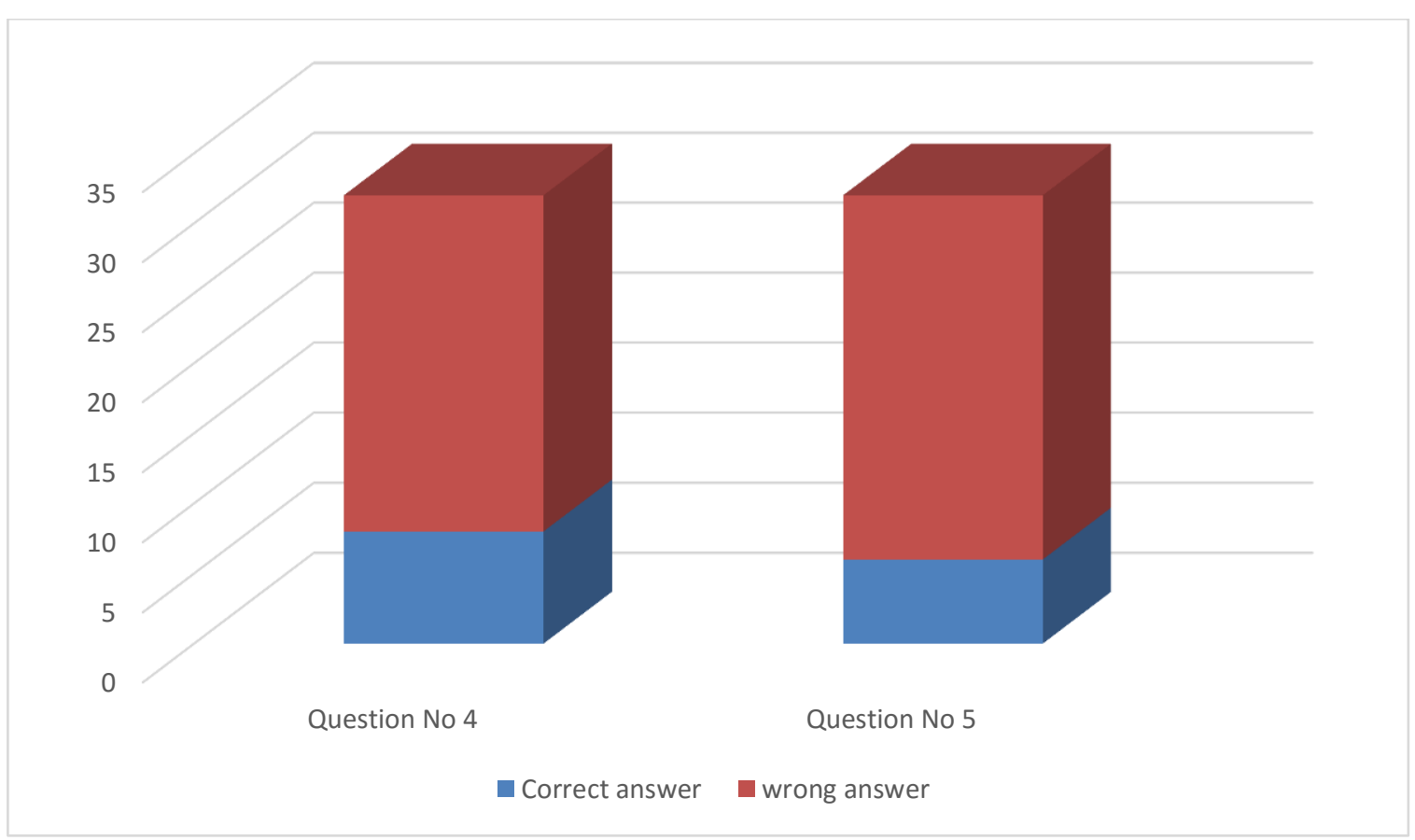

Figure 5. Chart Student Answer

\section{Conclusion}

The research result in learning identified material of circumference and area of a triangle were didactical, ontogenic and epistemological obstacle. As for learning obstacle found are: (1) distinguishing concept image material high line, bisecting line, 
line weight and line axis; (2) determine the high line on the triangular side of the base is not horizontal; (3) Determine the triangle area an obtuse triangle; and (4) visualization of the students regarding the ability to determine the type of triangle and the position of the perpendicular line or field

\section{References}

[1] Gutiérrez, Á. (1992). Exploring the links between Van Hiele Levels and 3dimensional geometry. Structural Topology 1992 núm 18.

[2] Tall, D. (2004). Thinking through three worlds of mathematics. In Proceedings of the 28th Conference of the International Group for the Psychology of Mathematics Education (Vol. 4, pp. 281-288).

[3] Bishop, A. J. (1989). A review of research on visualisation in mathematics education. DOCUMENT RESUME Proceedings of the Annual Conference of the International Group for the Psychology of Mathematics Education (12th, Veszprem, Hungary, July 20-25, 1988), Volume 1,p. 187.

[4] Mason, M. (2009). The van Hiele levels of geometric understanding. Colección Digital Eudoxus, 1(2).

[5] Schwartz, J.E. (2010). Why Learn Geometry? [Online] Update on Jul 20, 2010. Tersedia: http://www.education.com/reference/article/why-learngeometrymathematics/ [22 Juni 2015].

[6] Pegg, J. (1985). How Children Learn Geometry: The Van Hiele Theory. Australian Mathematics Teacher, 41(2), 5-8.

[7] Nasser, L. (1992). Using the van Hiele theory to improve secondary school geometry in Brazil (Doctoral dissertation, King's College London (University of London)).

[8] Usiskin, Z. (1982). Van Hiele Levels and Achievement in Secondary School Geometry. CDASSG Project.

[9] Wu, D. B., \& Ma, H. L. (2006, July). The distributions of van Hiele levels of geometric thinking among 1 st through 6 th graders. In Proceedings 30th conference of the international group for the psychology of mathematics education (Vol. 5, pp. 409-416).

[10] Saads, S., \& Davis, G. (1997). Spatial abilities, van Hiele levels \& language use in three dimensional geometry. In PME CONFERENCE (Vol. 4, pp. 4-104). The Program Committee Of The 18th PME Conference. 